\title{
Bruton's X-Linked Agammaglobulinemia Presenting as Chronic Monoarticular Arthritis
}

\author{
Kumar MK' ${ }^{1}$, Patel PK², Tahir Md MA³ \\ ${ }^{1}$ Dr. Mani Kant Kumar, MBBS, MD, Assistant Professor, ${ }^{3}$ Dr. Mohhamad Mahtab Ali Tahir, MBBS Junior Resident, both from \\ the Department of Paediatrics, ${ }^{2}$ Dr. Pankaj Kumar Patel, MBBS, MD, Assistant Professor, Department of Pathology. All \\ from the Narayan Medical College and Hospital, Jamuhar, Sasaram, Bihar, India.
}

Address for correspondence: Dr. Mani Kant Kumar, Email: manikant7@yahoo.com

\begin{abstract}
Bruton's X-Linked Agammaglobulinemia (XLA) is an X linked recessive primary immune deficiency disorder characterized by recurrent bacterial infections and failure to generate immunoglobulins of all isotypes due to the absence or profoundly decreased mature B cells and plasma cells, secondary to mutations in the Bruton's tyrosine kinase (Btk) gene. The coexistence of chronic monoarticular arthritis in a patient with Bruton's XLA has been described an uncommon presentation. We describe a 5 year-old boy with XLA and chronic monoarticular arthritis.
\end{abstract}

\section{Introduction}

$T^{\text {Te }}$ he adaptive immune response consists of humoral immunity mediated by B lymphocytes and cellular immunity maintained by $\mathrm{T}$ lymphocytes. Agammaglobulinemia was the first primary immunodeficiency to be described. In 1952, Colonel Ogden Bruton noted the absence of the "gammaglobulin" fraction on protein electrophoresis in a boy with recurrent bacterial sinopulmonary infections ${ }^{1}$. Bruton's X-linked agammaglobulinemia (XLA) is a humoral immunodeficiency disease caused by a mutation in the Bruton tyrosine kinase (BTK) gene at Xq21.3, resulting in defective $B$ cell differentiation and a decrease in all serum immunoglobulins ${ }^{2}$. The prevalence of XLA has been estimated at 1 case per 250,000 males in the United States. B-cell deficiencies or dysfunction lead to increased susceptibility to infection, especially with encapsulated pyogenic organisms, such as Streptococcus pneumoniae, Haemophilus influenzae, and Pseudomonas species. Pneumonia, sinusitis, meningitis, and bacterial diarrhea are common, as is an increased susceptibility to enteroviral infections ${ }^{3}$. The recurrent bacterial infections typical of XLA begin after 6 months of age when the maternally acquired transplacental antibody levels decrease and the infant is unable to synthesize antibodies normally. Chronic arthritis is an uncommon presentation of the XLA. We describe a 5 year old boy with Bruton's X-linked agammaglobulinemia presenting with chronic monoarticular arthritis.

\section{The Case}

A five year old boy presented with a history of pain and swelling of right knee joint for past one year, which had not improved with multiple doses of intravenous antimicrobials and a nine month course of anti-tubercular drugs. He had a history of recurrent pneumonia since six months of age which required hospitalization. He also had a history of chronic ear discharge, recurrent soft tissue infections and recurrent diarrhoea. He also had received six months course of anti tubercular drugs for pulmonary tuberculosis at the age of one year in view of recurrent lower respiratory infection. He was a product of non-consanguineous parents and had four sibling, three elder healthy sisters and one youngest brother. The youngest brother died due to pneumonia at the age one year, who also had history of recurrent pneumonia.

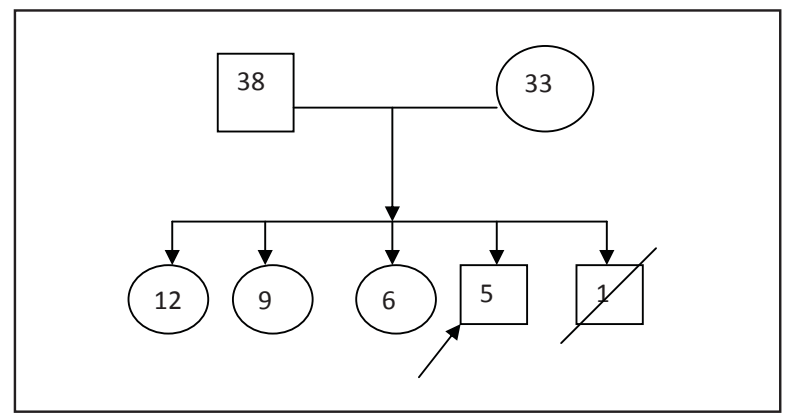

Fig 1: Showing pedigree chart of the family. 
On admission he was afebrile, and malnourished. He had mild pallor, pulse rate 98 per minute, respiratory rate of 32 per minute, weight $10 \mathrm{~kg}$ (less than $3 \mathrm{rd}$ centile), length $96 \mathrm{~cm}$ (less than $3 \mathrm{rd}$ centile), and multiple healed scars of boils all over body. Tonsils were atrophic and not even single lymph node was palpable in spite of recent abscess in the neck Figure 2. Right knee joint was swollen, and mildly tender. Cardiovascular and central nervous system examination were normal. Respiratory examination revealed bilateral crepts on inframammary and infrascapular areas. Liver was palpable $2 \mathrm{~cm}$ below right costal margin. Ophthalmological (Slit lamp and Fundus) examination was normal. On the basis of clinical history and examination findings, differential diagnosis were

1. Bruton's agammaglobulinemia,

2. Common variable immunodeficiency,

3. Secondary Immunodeficiency disorder (HIV Infections),

4. Hyper IgM syndrome and

5. Oligoarticular Juvenile Rheumatoid arthritis.

On laboratory workup, initial investigation findings (Table 1), which ruled out Secondary Immunodeficiency disorder (HIV Infections). Specific laboratory workup findings are shown in Table 2.

Table1: Showing Initial Investigation findings:

\begin{tabular}{|l|c|}
\hline \multicolumn{1}{|c|}{ Investigation } & Value \\
\hline Hemoglobin & $9.2 \mathrm{gm} / \mathrm{dl}$ \\
\hline Total Leukocytes Count & $6,200 / \mu \mathrm{l}$ \\
\hline Differential leukocytes count & $\mathrm{P} 69 \mathrm{~L} 28 \mathrm{E} 2 \mathrm{M} 1$ \\
\hline Platelets count & $320000 / \mu \mathrm{l}$ \\
\hline Rheumatoid Factor & Negative \\
\hline C-reactive Protein & Positive $(1.5 \mathrm{mg} / \mathrm{dl})$ \\
\hline Anti nuclear antibody (ELISA) & negative \\
\hline Blood Urea & $26 \mathrm{mg} / \mathrm{dl}$ \\
\hline Serum Creatinine & $0.6 \mathrm{mg} / \mathrm{dl}$ \\
\hline SGPT & $22 \mathrm{U} / \mathrm{L}$ \\
\hline $\mathrm{Na}+/ \mathrm{K}+/ \mathrm{Ca}++$ & $138 / 4.6 / 8.2$ \\
\hline HIV1 \& HIV2 & Negative \\
\hline
\end{tabular}

Chest X-ray PA view findings were suggestive of right mid zone patchy consolidation \& early bronchiectatic changes (Figure 2). Mantoux test and three consecutive days early morning gastric aspirates for Acid Fast Bacilli (AFB) were negative. Stool routine and microscopic examination showed cyst of Giardia Lambia. Laboratory evaluation of the synovial fluid revealed synovial fluid WBC 110 cells/mm3, India ink stain for Cryptococcus, Fungal stain, gram stain and AFB Stain were negative. Synovial fluid culture was sterile.

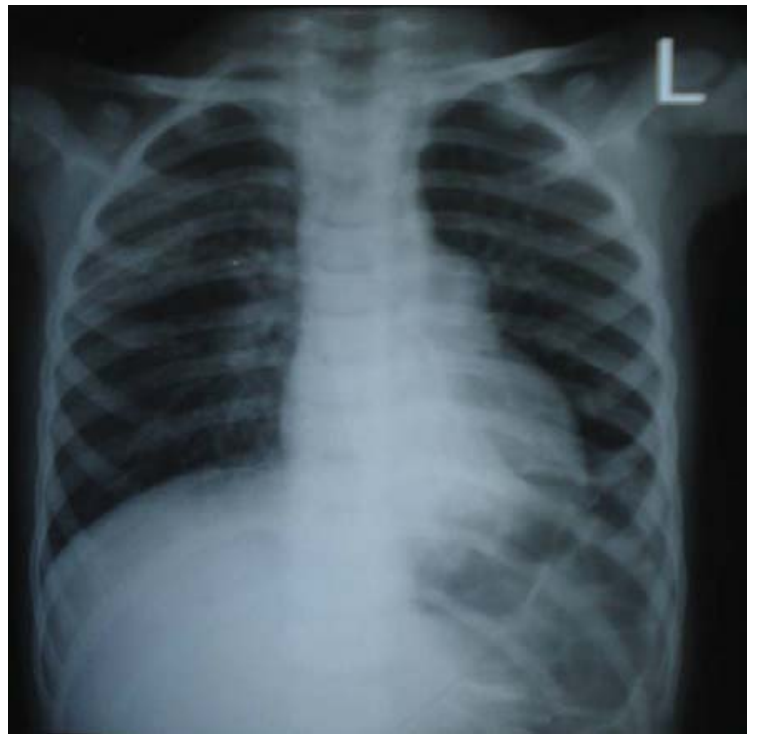

Fig 2: Chest X-ray PA view showing Right mid zone patchy consolidation \& early Bronchiectatic changes.

Table 2: Immunoglobulin and Immunophenotype Profile (SRL Ranbaxy Laboratories) of the patient.

\begin{tabular}{|c|c|}
\hline Investigations & Value \\
\hline $\lg G$ & $\begin{array}{l}60 \mathrm{mg} / \mathrm{dl} \text { (Normal- } 350 \mathrm{mg} / \\
\mathrm{dl}-1.2 \mathrm{gm} / \mathrm{dl})\end{array}$ \\
\hline $\lg A$ & $\begin{array}{l}5 \mathrm{mg} / \mathrm{dl} \text { (Normal- } 17 \mathrm{mg} / \\
\mathrm{dl}-318 \mathrm{mg} / \mathrm{dl})\end{array}$ \\
\hline $\lg M$ & $\begin{array}{l}26 \mathrm{mg} / \mathrm{dl} \text { (Normal- } 30 \mathrm{mg} / \\
\mathrm{dl}-265 \mathrm{mg} / \mathrm{dl} \text { ) }\end{array}$ \\
\hline $\lg \mathrm{E}$ & $\begin{array}{l}0 \text { (Normal } 1.7 \mathrm{IU} / \mathrm{ml}-58.4 \\
\mathrm{IU} / \mathrm{ml})\end{array}$ \\
\hline CD3 & 93\% (Normal 55-82 \%) \\
\hline CD19 & $0.06 \%$ (Normal- 09-29\%) \\
\hline $\begin{array}{l}\text { Btk protein expression in } \\
\text { monocytes }\end{array}$ & Absent \\
\hline
\end{tabular}

Patient was diagnosed as Bruton's Agammaglobulinemia with Chronic monoarticular arthritis and Giardiasis, and was managed with broad spectrum intra venous (IV) antimicrobials, IV Immunoglobulin replacement therapy @ 500mg/ $\mathrm{kg}, 7$ days course of metronidazole for giardiasis and Nutritional suppliments. Patient was discharged on CoTrimoxazole prophylaxis and nutritional supplements with advice of monthly IV Immunoglobulin replacement therapy @ 400mg/kg/month and regular follow up. On follow-up, right knee joint pain and swelling gradually subsided and there was no recurrent Sino-pulmonary and soft tissue infection. Over six months of follow up patient was doing well and gained two kg weight, but unfortunately patient was lost to follow up for past seven months. 
Table 3: Difference between XLA and CVID

\begin{tabular}{|l|l|l|}
\hline & Bruton's X-Linked Agammaglobulinemia (XLA) & \multicolumn{1}{|c|}{ CVID } \\
\hline Age of onset & Usually by 9-18 months & Usually 2nd - 4th decade \\
\hline $\begin{array}{l}\text { Family History of } \\
\text { immunodeficiency }\end{array}$ & Usually +ve & Variable \\
\hline Inheritance & X-linked recessive & Variable \\
\hline Lymph Nodes & Absent (Non Palpable) & Normal / Enlarged \\
\hline Tonsils & Absent / Atrophic tonsils & Normal tonsils \\
\hline CD19+ B cell numbers & Markedly decreased/absent & Normal/low \\
\hline CD3+T cell numbers & Normal & Variable \\
\hline Specific Antibody titers & Absent & Decreased/absent \\
\hline Mutations reported & Btk & TACl, ICOS, BAFF-R, CD19+ \\
\hline Common Complications & Infections & Infections \\
\hline & Allergy/Atopy & Allergy/Atopy \\
\hline & Autoimmunity & Autoimmunity \\
\hline & Malignancy & Malignancy \\
\hline Treatment & IV Immunoglobulin (IV IG) & IV Immunoglobulin (IV IG) \\
\hline
\end{tabular}

Table 4: Difference between XLA and Hyper IgM Syndrome

\begin{tabular}{|l|l|l|}
\hline \multicolumn{1}{|c|}{} & \multicolumn{1}{|c|}{$\begin{array}{c}\text { Bruton's X-Linked } \\
\text { Agammaglobulinemia(XLA) }\end{array}$} & \multicolumn{1}{c|}{ Hyper IgM syndrome } \\
\hline Age of onset & Usually by 9-18 months & Usually 1-2 year \\
\hline Family History of immunodeficiency & Usually +ve & Variable \\
\hline Inheritance & X-linked recessive & Variable \\
\hline Lymph Nodes & Absent (Non Palpable) & Non Palpable \\
\hline Tonsils & Absent / Atrophic tonsils & Small tonsils \\
\hline Neutrophil count & Normal & Decreased \\
\hline CD19+'B cell numbers & Markedly decreased/absent & Normal \\
\hline CD3+T cell numbers & Normal & Normal \\
\hline IgM & Decreased & Normal/Elevated \\
\hline IgG \& IgA & Markedly decreased & Markedly Decreased \\
\hline Mutation & Btk gene & CD 40 Ligand \\
\hline Clinical Presentation & Recurrent pyogenic infections & Recurrent Pyogenic Infections \\
\hline & Autoimmunity & Autoimmunity \\
\hline & Malignancy & Malignancy \\
\hline Treatment & IV Immunoglobulin (IVIG) & IVIG, G-CSF, Stem cell Transplant \\
\hline
\end{tabular}

\section{Discussion}

Our case was a definite case of Bruton's X-linked agammaglobulinemia (XLA), based on standard criteria described below ${ }^{4}$.

\section{Diagnostic Criteria}

Definitive: A male patient with less than $2 \%$ CD19 B cells and at least one of the following findings is present.

1. Mutation in BTK gene.

2. Absence of BTK mRNA on northern blot analysis of neutrophils or monocytes.

3. Absence of BTK protein in monocytes or platelets.

4. Maternal cousins, uncles, or nephews with less than $2 \%$ CD19 B cells.
Probable: A male patient with less than 2\% CD19 B cells in whom all of the following findings are present:

1. Recurrent bacterial infections in the first 5 years of life.

2. Serum $\lg G$, $\lg M$, and $\lg A$ more than 2 SD below normal for the patient's age.

3. Absent isohemagglutinins and/or poor response to vaccines.

4. Other causes of hypogammaglobulinemia have been excluded.

Possible: A male patient with less than 2\% CD19 B cells in whom other causes of hypogammaglobulinemia have been excluded and at least one of the following findings is present: 
1. Recurrent bacterial infections in the first 5 years of life.

2. Serum $\lg G$, $\lg M$, and $\lg A$ more than $2 \mathrm{SD}$ below normal for the age.

3. Absence of isohemagglutinins.

Knowledge of the key characteristics of Bruton's X-linked Agammaglobulinemia (XLA) and Common variable immunodeficiency (CVID) may assist in the differentiation of these two clinically similar diseases (Table 3). XLA and CVID are both humoral immunodeficiencies that can manifest similar clinical presentations in male child 5 .

Bruton's X-Linked Agammaglobulinemia(XLA) can be differentiated with Hyper IgM syndrome as shown in Table $4^{6}$.

Oligo-articular Juvenile Rheumatoid arthritis (JRA) describes the involvement of 4 or fewer joints and affects an estimated $40-60 \%$ of children with JRA. At least two distinct subgroups have been identified: Early childhood onset (frequently associated with positive anti-nuclear antibodies and iridocyclitis) and late childhood onset.

Early childhood onset Oligo-articular JRA affects predominantly girls under the age of 6 years. More common in Caucasian children, it accounts for about $30-40 \%$ of patients with JRA. About $50 \%$ have monoarticular arthritis. Large joints of the lower extremities are most often involved, including knees and ankles, occasionally elbows. This subtype is associated with positive ANAs (anti-nuclear antibodies) and chronic iridocyclitis.

The late childhood onset Oligo-articular JRA is associated with HLA B27 and development of enthesitis and sacroiliitis. It affects approximately $10-15 \%$ of children with JRA. There is a male predominance with the age of onset usually after 8 years of age. A family history of spondyloarthropathy such as ankylosing spondylitis, Reiter's disease, inflammatory bowel disease with spondylitis, psoriatic arthritis, and acute iridocyclitis is often obtained.

Nonsteroidal anti-inflammatory drugs (NSAIDs) are important initial agents in the treatment of JRA. Methotrexate is an effective agent in children with severe JRA and is frequently used to treat children who have failed to respond to NSAIDs. (Sulfasalazine may be effective in treatment of JRA, although drug toxicity may be a problem ${ }^{7,8}$.

This case was a five year old male child with only one joint involvement, normal ophthalmological (Slit lamp and fundus) examination, negative anti-nuclear antibodies (ANAs), Negative rheumatoid factor (RF) and no significant response to non steroidal antiinflammatory drugs. Thus in this case Oligo-articular JRA was excluded.

This case presented predominantly as chronic monoarticular arthritis which is an uncommon manifestation of XLA. In different studies arthritis was reported as predominant manifestation in $11 \%$ to $20 \%$ of $X L A^{9,10}$.

Although most children with XLA develop recurrent bacterial respiratory tract infections during infancy, 20\% are diagnosed in children aged 3-5 years, reflecting the widespread use of antibiotics. Unfortunately, permanent damage to the lungs with bronchiectasis may have already occurred ${ }^{11}$ as in our case, which was diagnosed at 5 years of age, already had bronchiectasis.

This case also had chronic diarrhea caused by Giardia lambia. XLA patients often suffer chronic enteroviral infections, persistent rotaviral infection, chronic diarrhea by Giardia lamblia, and other persistent infections as a result of incomplete eradication of antigen due to humoral immunodeficiency ${ }^{12}$.

Early IVGG replacement therapy decreased the rates of admission and morbidity for chronic complications, such as bronchiectasis and chronic lung disease, and prevented fatal complications like meningoencephalitis ${ }^{13}$. Lederman $\mathrm{HM}$ et al, in a large series reported that appropriate IV immunoglobulin replacement therapy should be started at six to eight weeks of age because around $25 \%$ of the XLA patients show clinical symptoms before 4 months of age ${ }^{9}$.

After the infant period, more than three occurrences of otitis media and sinusitis, the absence of tonsils, and the presence of scanty cervical lymph nodes are indications to check serum immunoglobulin levels. If the levels of more than two types of immunoglobulin are decreased, XLA should be suspected ${ }^{13}$. XLA is a well-known immunodeficiency disease for which early diagnosis and proper management is possible with high index of suspicion.

\section{Vaccinations}

Live vaccine (especially oral polio vaccine in developing countries) should be avoided, and only the inactivated vaccine should be used. This is because even the weaker virus in the orally administered vaccine may give rise to a polio infection in an individual with $\mathrm{X}$-linked agammaglobulinemia. Further, no live oral polio vaccine should be administered to close household contacts, as the virus is secreted through the feces for some time after vaccination, and there is a risk that it will spread ${ }^{14}$. 
Killed vaccines can be safely given, but they often have little or no effect, since the antibodies in the immunoglobulin infusions administered to the child deactivate the vaccine before it can trigger an immune response ${ }^{14}$.

Fortunately, this case didn't have any negative consequences due to the live vaccines they received as standard care and during pulse polio immunization program prior to diagnosis. This phenomenon might be explained by the fact that T cell function in XLA is not impaired, so partial immune defence mechanisms can compensate for impaired humoral immunity ${ }^{15}$.

\section{Conclusion}

Bruton's X-linked agammaglobulinemia (XLA) is a well-known immunodeficiency disease for which early diagnosis and proper management is possible if physicians have a high index of suspicion for this disease. Uncommonly XLA can manifest with varied phenotypes like chronic arthritis. Early IV IgG replacement therapy decreased the rates of admission and morbidity for chronic complications (13). Live vaccine (especially oral polio Vaccine) shoud be avoided, and only the inactivated vaccine should be used.

\section{References}

1. O. C. Bruton, "Agammaglobulinemia," Pediatrics 1952;9(6):722-27.

2. Conley ME, Rohrer J, Minegishi Y. X-linked agammaglobulinemia. Clin Rev Allergy Immunol 2000;19:183-204.

3. R. E. Petty and R. M. Laxer, Textbook of Pediatric Rheumatology, edited by J. T. Cassidy, R. E. Petty, R. M. Laxer, and C. B. Lindsley, Elsevier Saunders, 5th edition, 2005.

4. Conley ME, Notarangelo LD, Etzioni A. Diagnostic criteria for primary immunodeficiencies. Representing PAGID (Pan-American Group for Immunodeficiency) and ESID (European Society for Immunodeficiencies) Clin Immunol. 1999;93:190-97.
5. Spickett, G. P. Current perspectives on common variable immunodeficiency (CVID). Clin Experimen Allerg 2001;31:536-42.

6. Jacov Levy, Teresa Espanol-Boren, Carolin Thomas, Alain Fischer, et al. Clinical spectrum of X-linked hyper-IgM syndrome. J Pediatr 1997;131:47-54.

7. Cassidy JT, Petty RE (eds). Textbook of Pediatric Rheumatology, 4th ed. 2001. Philadelphia: W.B. Saunders.

8. Ilowite N. Current Treatment of Juvenile Rheumatoid Arthritis. Pediatrics 2002;109(1):109-115.

9. Lederman HM, Winkelstein JA. X-linked agammaglobulinemia: an analysis of 96 patients. Medicine (Baltimore) 1985;64:145-156.

10. Hermaszewski RA, Webster ADB. X-Linked Agammaglobulinemia- a survey of clinical manifestations and complications. Quart J Med 1993;86:31-42.

11. Conley ME, Howard V. Clinical findings leading to the diagnosis of $\mathrm{X}$-linked agammaglobulinemia. J Pediatr 2002;141:566-71.

12. Halliday E, Winkelstein J, Webster AD. Enteroviral infections in primary immunodeficiency (PID): a survey of morbidity and mortality. J Infect. 2003;46:1-8.

13. Winkelstein JA, Marino MC, Lederman HM, Jones SM, Sullivan K, Burks AW, et al. X-linked agammaglobulinemia: report on a United States registry of 201 patients. Medicine (Baltimore) 2006;85:193-202.

14. Indian Academy of Pediatrics, Committee on Immunization 2009-2011. Immunization in special situations. IAP Guide Book on Immunization 2011. p 147-54.

15. Minor PD. Biosafety consequences of eradication of wild-type polioviruses. Lancet. 2001;358:166-68.

\section{How to cite this article?}

Kumar MK, Patel PK, Tahir Md MA. Bruton's X-Linked Agammaglobulinemia Presenting as Chronic Monoarticular Arthritis. J Nepal Paediatr Soc 2012;32(3):245-249. 